\title{
Parental Mental Health Problems and the Risk of Child Maltreatment: The Potential Role of Psychotherapy
}

\author{
Ana Isabel Lopes ${ }^{1} \mathbb{D}$, João Leal ${ }^{1,2,3}$ and Ana Isabel Sani ${ }^{1,4, *(\mathbb{D})}$ \\ 1 Faculty of Human and Social Sciences, University Fernando Pessoa (UFP), Praça 9 de Abril 349, \\ 4249-004 Porto, Portugal; isabelpinheirolopes@protonmail.com (A.I.L.); joaolsilva@ufp.edu.pt (J.L.) \\ 2 Department of Social and Behavioral Sciences, University of Maia (ISMAI), 4475-690 Maia, Portugal \\ 3 Center of Psychology, University of Porto, 4099-002 Porto, Portugal \\ 4 Research Centre on Child Studies (CIEC), University of Minho, 4704-553 Braga, Portugal \\ * Correspondence: anasani@ufp.edu.pt
}

Citation: Lopes, A.I.; Leal, J.; Sani, A.I. Parental Mental Health Problems and the Risk of Child Maltreatment: The Potential Role of Psychotherapy. Societies 2021, 11, 108. https:// doi.org/10.3390/soc11030108

Academic Editor: Ian Kelvin Hyslop

Received: 23 July 2021

Accepted: 30 August 2021

Published: 5 September 2021

Publisher's Note: MDPI stays neutral with regard to jurisdictional claims in published maps and institutional affiliations.

Copyright: (c) 2021 by the authors. Licensee MDPI, Basel, Switzerland. This article is an open access article distributed under the terms and conditions of the Creative Commons Attribution (CC BY) license (https:/ / creativecommons.org/licenses/by/ $4.0 /)$.

\begin{abstract}
Parental mental health is a risk factor for numerous issues affecting a child's physical and psychological development, especially the perpetration of child maltreatment. This paper aims to contribute a theoretical review of the risks faced by some children living in families with parental mental health problems and argues that psychotherapy has an essential role in resolving emotional and interpersonal difficulties, based on the example of Emotion Focused Therapy (EFT). This model has revealed benefits in interventions with several types of patients and is consequently a promising model for preventing the risk of aggressive behaviors. The programs addressing both parents and children have been proven to contribute to more informed and effective interventions.
\end{abstract}

Keywords: child maltreatment; parental mental health; Emotion Focused Therapy (EFT)

\section{Introduction}

Children and adolescents around the world face several risks during their development, many of which are directly or indirectly caused by people who are part of their family circle [1]. The adversities of a child's life at home, school, or community, whether caused by natural accidents, armed conflicts, loss/grief, victimization by action (physical, psychological, or sexual abuse), or omission (negligence), can hinder the child's safety, stability, and attachment bond [2]. Among the multiplicity of experiences that contribute to children's well-being and development, those that are identified as having a significant adverse influence are maltreatment, negligence, and parental mental disorders $[3,4]$.

Research has shown that there is a relation between parental mental disorders and child abuse [5-7] and that different psychiatric conditions have distinct influences on the child's development. The degree and the quality of those effects are dependent on several factors, among them the severity, chronicity, and type of incapacity experienced by parents who suffer from a mental disorder and other individual, parent, family, and community factors [8]. Mood and personality disorders are examples of conditions that are particularly harmful in a household environment. Nevertheless, some types of psychiatric disorder (e.g., personality or psychotic disorders) are more challenging than others, specifically disorders with more severe symptomatology (e.g., suicide risk, psychotic behaviour) [7]. Therefore, for adult parents who suffer from mental health problems, an effective intervention is extremely important to ease their psychological suffering, as well as to contribute to, among other goals, a reduction in the risk of child/juvenile victimization [9-11].

Based on the clinical, academic and research experience of the authors we produced an integrated review of international empirical studies exclusively on the problem in this article, which have been produced and critically evaluated in the last two decades. The method used aimed to theoretically and scientifically substantiate our argument for the 
urgency of an interventional approach oriented towards the protection and well-being of children living in families with parental mental health problems.

In this paper, we focus on parental mental health as one of the most significant predictors of child maltreatment (cf. Figure 1), a widespread problem that needs to be tackled, although sometimes there are barriers to access prevention services [12]. In this analysis, different factors will be considered in relation to child maltreatment, such as: type of parental psychopathology; severity; absence of treatment; and drug and alcohol consumption. The relevance of the topic under study is in the gap in finding articles in the reviewed literature in this area that will present a concrete proposal for psychotherapy with parents with mental health problems, demonstrating simultaneously how this intervention can be promising in reducing risk and promoting the wellbeing of a child. After a brief review of the literature this article ends describing how psychotherapy, in particular, Emotion Focused Therapy (EFT), can have an essential role in helping parents and families resolve emotional and interpersonal problems that may increase the risk of child maltreatment.

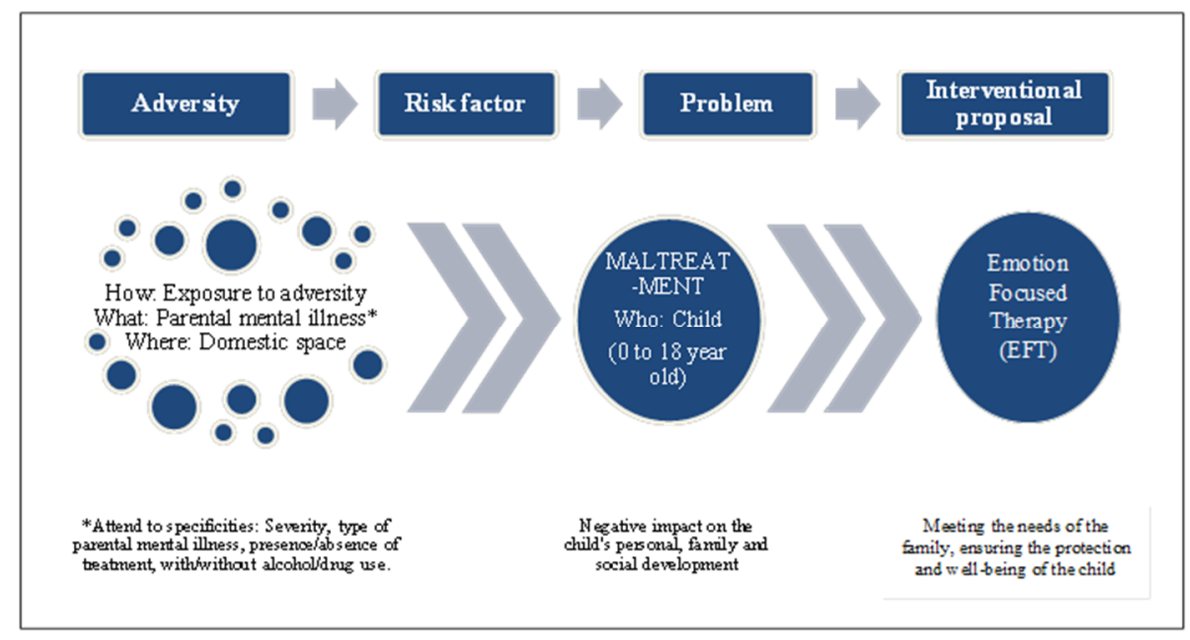

Figure 1. Schematic overview of the analytical and theoretical dimensions of the proposal under discussion.

\section{Impact of Exposure to Parental Mental Health Problems on Child Psychological Development}

Children living with parents suffering from mental disorders may face a higher risk of developing mental health problems and adjustment problems and have an increased risk of death as a consequence of parental psychiatric symptoms or clinical decompensation $[13,14]$. These risks may be due to a general vulnerability, including both genetic and environmental factors, for example the deficient interactions between caregiver and child [8,15]. According to the authors of [16], parental health problems are one of the strongest predictors of child neglect. Situational factors, such as child abuse and other adverse experiences are also frequently found in these families [15].

The child's risk of developing a psychiatric disorder is influenced by the type of disorder suffered by the caregiver, its severity, age of onset [15], and current symptoms, all of which can impact on parental skills, and the care and interaction with the child [8]. In this context, minors will assume inappropriate responsibilities which will hinder their academic activity. This is a large-scale issue: Bassani et al. [13] reported that one in ten Canadian children under 12 years old lived with a parent suffering from a psychiatric disorder.

Oskouie et al. [17], in a study of young adults with parents undergoing monitoring by a psychiatric hospital highlighted the different areas affected by parental mental health: interpersonal relationships, a higher tendency toward isolation affecting social support; mental health, with a higher propensity to develop anxiety, low self-esteem and fear 
of developing the same illness; negative economic impact; a reduction in educational opportunities; and the appropriation of adult role(s).

Slominski [18] concluded that individuals with a maternal mental health history had a higher probability of developing mental disorders in adulthood, had more anxiety, experienced avoidance in intimate relationships, and secured lower-grade academic qualifications and jobs. Maternal mental health disorders were also associated with more unstable parenting and conflicting family dynamics. More specifically, the results of Brennan et al. [19], based on a sample of 522 Australian families, showed that parental depression influenced externalization disorders in adolescents. Additionally, their study also verified that the risk of developing a mental disorder by an adolescent increases when one parent suffers from a mental disorder and another has a substance abuse problem. The preventive interventions with children of mentally ill parents may decrease the risk of the intergenerational transmission of mental disorders [20] and strong collaboration between Child and Adolescent Mental Health Services and Adult Mental Health Services could address the needs of these children [21].

\section{Parental Mental Health as a Risk Factor for Child Abuse}

Exposure to a parental mental disorder can have several impacts which affect a child's personal, familial and social development up to adulthood [18]. Several studies, with different methodologies, have identified parental mental health as a risk factor for child abuse $[5,7,15,22-24]$. Abusive parents present higher levels of mental disorder in comparison to control groups or to rates of mental disorder in the general population [23], although not all children and adolescents are at risk of victimization [25].

Parental mental illness is a risk factor with a dynamic effect; it varies according to the intrinsic characteristics of the mental disorder (e.g., the type and severity of symptoms, insight) and extrinsic factors (e.g., treatment and secondary effects; family, community and socioeconomic support; the presence of another caregiver; the age and phase of child's development) $[8,11,26]$. Thus, the mental illness affects parenting skills and these, in turn, will have an impact on the risk of child abuse.

Symptoms such as emotional numbness, avoidance, anhedonia, restricted affect, sleep disorder, difficulties in concentrating, and irritability harm parental competency and are linked to child negligence [27]. These symptoms are frequently associated with bipolar disorder, depression, anxiety, schizophrenia, and post-traumatic stress disorders. Moreover, De Bellis et al. [23] observed that in cases of abuse and negligence, mothers who display a higher number of symptoms such as despair, low self-esteem, low levels of concentration, anhedonia, and disassociation are more likely to withhold protection from their offspring. The same researchers found no predominant type of psychiatric disturbance in abusive parents. In their study sample, the mothers exhibited higher rates of mood disorders (72\%); anxiety disorders ( $43 \%$ of post-traumatic stress disorders were related to domestic violence and child sexual abuse); suicide attempts; and comorbidity with two or more nonpsychotic psychiatric disorders ( $83 \%$ of the mothers with post-traumatic stress disorder also suffered from a mood disturbance), in comparison to the control group [23]. Along the same lines, the study of Johnson et al. [28] reported an association between several psychiatric disturbances and problematic maternal behaviour (including abuse and neglect), specifically anxiety, depression and, most frequently, personality disorders. Furthermore, paternal depression and maternal non-specific psychiatric disorders were nominated by Sidebotham, Golding, and The ALSPAC Study Team [29] as the most significant variables related to child abuse.

In a study of mothers who suffered from psychotic disturbances, their children were interviewed as adults regarding their childhood experiences [30]. Participants described abuse or neglect, and in one case, sexual abuse. The study also noted that, due to the mothers' distorted notion of reality, their ability to satisfy their children's basic needs was severely impaired. 
In the literature that explores parental mental disorders in relation to child maltreatment (e.g., $[10,11,13,23,26,28,31-37])$, there are three aspects that emerge: (i) lack of adequate treatment; (ii) drug and alcohol abuse; (iii) personality disorders.

\subsection{Lack of Adequate Treatment}

One of the motives for studying the risk of violence in cases of parental mental disorder is to inform professional assessment and monitoring: if the parent is adequately treated and their symptoms brought under control, the risk of violence is not expected to increase $[26,28]$.

Friedman and McEwan [26] concluded that parents with a psychiatric disorder that is under treatment present a lower risk of child abuse than other parents in the community. After 10 weeks of medical discharge, $5 \%$ of the participants perpetrated child abuse, in comparison to $14 \%$ of the individuals in the control group. Of the $5 \%$, the abusive parents were categorised by diagnosis: $8 \%$ had a severe mental illness; $3 \%$ had an issue with drug abuse, and $4 \%$ had a mental illness and an issue with drug abuse. Parents experiencing delirium at the time of their interviews were more likely to perpetrate violence on their children in the following ten-week period.

In a longitudinal study by Johnson et al. [28] with a community-based sample, less than one in three mothers reported having received psychiatric treatment and those who reported it had a lower probability of experiencing difficulties in their parental role. In addition, Bassani et al. [13] observed that most parents who suffered from mental health problems reported a lack of mental health care in the previous 12 months (prior to interview).

\subsection{Drug and Alcohol Abuse}

Parental drug consumption, alcohol abuse or an addiction disorder can severely compromise parenting skills and are associated with physical abuse, child neglect and infanticide $[10,28]$. The risk of abuse and neglect of a minor is higher when mental disorders, personality disorders and learning disabilities are cumulatively associated [11,31]. Alongside child abuse, drug and/or alcohol abuse are also related to poverty, domestic violence, exposure to criminality and social isolation [11].

Male caregivers and mothers' intimate partners have a higher probability of being involved in substance abuse in comparison to female caregivers [11,23]. De Bellis et al. [23] observed an incidence of this problem in $32 \%$ of female caregivers, compared to $85 \%$ of male caregivers/partners. Additionally, the male participants perpetrated more acts of violence and child neglect than female participants.

\subsection{Personality Disorders}

In research on child abuse risk factors, personality disorders have been treated as distinct from other general mental disorders. Their presence in parenthood culminates in strict and problematic parental actions, as well as the perpetration of acts of violence $[10,11,28,32-37]$.

Individuals who suffer from personality disorders have maladjusted alert and affection systems and in parenthood may find it difficult to satisfy their child's emotional needs, as they may experience fear and/or hostility causing them to resort to previously learned behaviours (e.g., past abusive behaviour) [11]. In the study of Laulik et al. (2013) [34], in addition to a personality disorder being associated with low levels of affection and inadequate communication, this disorder was also associated with inconsistent parental discipline, problematic parental practices and child abuse. Wiehe [37] observed that parents who abuse their children have more narcissistic traits and lower impulse control than the control group. The author also stated that self-centredness and a lack of empathy in these individuals shaped the interpretation of their children's behaviour (e.g., harming a peer, not keeping their room clean) as disrespectful to their authority, which, in turn, triggered the perpetration of acts of violence. 
Several studies have suggested that amongst personality disorders, it is antisocial, borderline and narcissistic personality disorders (also known as cluster B) that are most strongly associated with child abuse perpetration [32,33]. According to Adshead [32], this risk increases when the offender is involved in substance abuse, is subjected to stressful situations or is coupled with a partner with another personality disorder. Stepp et al. [36] stated that female caregivers with borderline personality disorder presented critical, intrusive and frightening behaviours and reported higher levels of anguish in their parental role that, in turn, can lead to child abuse.

\section{Treatment of Parental Mental Disorders and Prevention of Child Abuse}

In mitigating the risk of child abuse it is necessary to identify the role that mental health and its associated factors play in order to consider the most appropriate possibilities for effective treatment [23]. It is necessary to consider the prognosis of the parental mental disorder, the individual's insight, their treatment adherence and also to identify (previously mentioned) extrinsic factors [11]. Evaluations of an individual should include, for example, whether the focus of the delirium or hallucinations involves the child(ren) (e.g., to harm them), whether the individual is too ill/worried to satisfy their basic needs and/or is abusing substances $[10,11]$.

In addition to the impacts caused by the mental disorder, the situation per se and the related risk factors, other parental competences to be assessed include basic and emotional care, communication style, conflict resolution and family rules [10]. Parental assessment must be executed in a period of remission or stabilization, although one must anticipate the possibility of a relapse. Many individuals have insight into their mental health condition and its implications for child custody [11], so they may not disclose severe symptoms or difficulties in their parental role. Beyond the risk assessment, the technician must foster parental coping skills, for example Seeman [38] suggested the auto-identification of relapse signs, the development of a crisis plan and a daily record of parental activities.

In addition to an intervention with the parent, the technician must conduct a structured interview with the child and collect information from several sources, such as family and child protection services [10,34]. Dunn [30], in considering interventions with minors, drew attention to the possibility of a conflicting or negative interview with a child, due to their sense of guilt in relation to their feelings of loyalty toward their parents. The psychoeducational intervention on mental disorders with the children of parents with mental illness is, therefore, extremely important for the well-being of these children [20,39].

Alongside treatment for parents with mental health problems and substance abuse, it is important to provide services to meet the needs of children and adolescents. There are some successful programs and projects (e.g., $[9,36,40]$ ) which can serve as models for intervention in families dealing with parental mental health problems or substance abuse. In this context, it is appropriate to adopt programs that provide integrated interventions that meet the needs of a family (as a system) rather than interventions targeted at individuals alone [41]. Some programs include innovative public-private cooperation, for example those involving child protection services and services that aim to treat caregivers [40]. The interventions addressing parents and children jointly produced overall larger effects [42].

\section{Potentialities of Psychotherapy: Emotion-Focused Therapy as an Example}

Emotion-focused therapy (EFT) is an experiential model of psychotherapy that views emotion as an essentially adaptive resource that enables people to identify and organise personally important information provided by internal and external cues, influences action tendencies toward personally relevant goals and helps people to make sense of themselves, others and the world [43]. A significant amount of research on this model of therapy has provided evidence of its efficacy for treating a wide range of clinical presentations, such as complex trauma [44], depression [45], generalised anxiety [46,47], social anxiety [48] and families with children with eating disorders [49]. 
Emotion-focused therapists help clients with their difficulties, problems or complaints by facilitating emotional awareness, expression, reflection, regulation and transformation [50] within an emotionally attuned and transformative relationship [51]. In-session, emotion-focused therapists focus on specific indicators of emotional processing difficulties (markers) and propose experiential and gestalt-inspired tasks to help clients resolve them (e.g., empty chair) [52,53]. Therefore, this process-oriented approach contrasts with more structured intervention models, usually delivered in pre-designed modules, due to its moment-by-moment attunement to the client's needs, and associated therapeutic interventions specifically proposed to help them with a present difficulty. Nonetheless, the process of therapy typically unfolds in three distinct but often overlapping phases: (a) bonding and emotional awareness, (b) evoking and exploration, and (c) emotional transformation [50].

Although there is a lack of research on EFT that includes child maltreatment as a dependent variable, this model of psychotherapy has already been tailored to address personality disorders [54], male offenders of intimate partner violence [55] and a range of anger difficulties [56] and is currently being developed to help clients victimised by intimate partners [57]. It seems, therefore, reasonable to assume that, pending further developments, EFT may be a valid intervention to prevent and/or mitigate the negative developmental, systemic and intergenerational effects of child maltreatment.

\section{Conclusions}

Violence negatively affects child and adolescent development, and its incidence is related to individual and situational variables associated with a child's caregivers. Instability, due to the mental health problems of caregivers, is a part of the human experience of numerous children around the world. The risk of child abuse can stem from the lack of quality care given to the child; the responsibilities demanded of these minors surpasses the physical and mental capacities at their stage of development. Family adversity can differ from case to case due to a set of factors and can generate other risks such as child and juvenile violence, which in turn can lead to increased incidence of mental health disorders in adulthood. Interventions that aim to foster the child's protection and well-being must take an integrated approach to meeting the needs of the whole family, for example by addressing the caretaker's mental health problems and/or alcohol and drug abuse, and/or preventing other phenomena associated with increased risk of child abuse. In the intervention with people struggling with mental health difficulties, several models are effective in reducing clinical symptoms, including the reduction in aggressive behavior in the context of interpersonal relationships in adults and children (cf. particular references to the models suggested). For example, cognitive behavioral therapy for families with children in child protection programs [58], and family systems therapy for children at high-risk of drug abuse [59]. In this article we briefly discussed an Emotion Focused Therapy (EFT) model, extensively tested for a wide range of emotional and interpersonal difficulties, to promote the development of research capable of testing the effectiveness of psychotherapeutic models with families struggling with mental health problems, to reduce risk of child maltreatment. This paper aims then, to contribute to the creation of intervention proposals based on an integrated approach that meets the needs of the whole family.

Author Contributions: A.I.L. was involved in the conceptualization and writing-original draft preparation. J.L. was involved in the manuscript writing. A.I.S. was involved in the conceptualization, writing - original draft preparation, review, editing and the final revision. She is also responsible for funding acquisition. All authors have read and agreed to the published version of the manuscript.

Funding: This work was financially supported by Portuguese national funds through the FCT (Foundation for Science and Technology) within the framework of the CIEC (Research Center for Child Studies of the University of Minho) projects under the references UIDB/00317/2020 and UIDP/00317/2020.

Conflicts of Interest: The authors declare no conflict of interest. 


\section{References}

1. Sani, A.I.; Lopes, A. Children's multiple violence exposure: Risk, impacts and intervention. In Violence Exposure: Perspectives, Gender Differences and Outcomes; Xu, S.A., Ed.; Nova Science Publishers: New York, NY, USA, 2019; pp. 79-99.

2. Center for Disease Control and Prevention. Preventing Adverse Childhood Experiences (ACEs): Leveraging the Best Available Evidence; Division of Violence Prevention, National Center for Injury Prevention and Control: Atlanta, GA, USA, 2019. Available online: http:/ / stacks.cdc.gov/view/cdc/82316/ (accessed on 20 July 2021).

3. Kessler, R.C.; McLaughlin, K.A.; Green, J.G.; Gruber, M.J.; Sampson, N.A.; Zaslavsky, A.M.; Aguilar-Gaxiola, S.; Alhamzawi, A.O.; Alonso, J.; Angermeyer, M.; et al. Childhood Adversities and Adult Psychopathology in the WHO World Mental Health Surveys. Br. J. Psychiatry 2010, 197, 378-385. [CrossRef] [PubMed]

4. Sani, A.I.; Lopes, A.I. Police intervention in cases of domestic violence against women and their exposed children. In Violence against Women in the 21st Century: Challenges and Future Directions; Guggisberg, M., Henricksen, J., Eds.; Science Publishers: New York, NU, USA, 2018; pp. 211-236.

5. Cooklin, A. Children as carers of parents with mental illness. Psychiatry 2009, 8, 17-20. [CrossRef]

6. O'Donnell, M.; Maclean, M.J.; Sims, S.; Morgan, V.A.; Leonard, H.; Stanley, F.J. Maternal mental health and the risk of child protection involvement: Mental health diagnoses associated with increased risk. J. Epidemiol. Community Health 2015, 69, 1175-1183. [CrossRef]

7. Reupert, A.E.; Maybery, D.J. What do we know about families where parents have a mental illness? A systematic review. Child Youth Serv. 2015, 37, 98-111. [CrossRef]

8. Reupert, A.E.; Maybery, D.J.; Kowalenko, N.M. Children whose parents have a mental illness: Prevalence, need and treatment. Med. J. Aust. 2012, 199, S7-S9. [CrossRef]

9. Hefti, S.; Pérez, T.; Fürstenau, U.; Rhiner, B.; Swenson, C.C.; Schmid, M. Multisystemic therapy for child abuse and neglect: Do parents show improvement in parental mental health problems and parental stress? J. Marital. Fam. Ther. 2020, 46, 95-109. [CrossRef] [PubMed]

10. Royal College of Psychiatrists. Child Abuse and Neglect: The Role of Mental Health Services; Royal College of Psychiatrists: London, UK, 2004. Available online: http:/ / www.southernhealth.nhs.uk/EasySiteWeb/GatewayLink.aspx?alId=13402 (accessed on 2 July 2021).

11. Royal College of Psychiatrists. Parents as Patients: Supporting the Needs of Patients Who Are Parents and Their Children; Royal College of Psychiatrists: London, UK, 2011. Available online: https:/ /www.rcpsych.ac.uk/docs/default-source/improving-care/bettermh-policy / college-reports / college-report-cr164.pdf?sfvrsn=79416179_2 (accessed on 2 July 2021).

12. Maguire-Jack, K.; Negash, T. Barriers in access to child maltreatment prevention programs for families involved with child protective services. J. Child Custody 2015, 12, 152-174. [CrossRef]

13. Bassani, D.; Padoin, C.; Philipp, D.; Veldhuizen, S. Estimating the number of children exposed to parental psychiatric disorders through a national health survey. Child Adolesc. Psychiatry Ment. Health 2009, 3, 6. [CrossRef]

14. Whitaker, R.C.; Orzol, S.M.; Kahn, R.S. Maternal mental health, substance use, and domestic violence in the year after delivery and subsequent behavior problems in children at age 3 years. Arch. Gen. Psychiatry 2006, 63, 551-560. [CrossRef]

15. Mattejat, F.; Remschmidt, H. The children of mentally ill parents. Deustches Arztebl. Int. 2008, 105, 413-418. [CrossRef] [PubMed]

16. Mulder, T.M.; Kuiper, K.C.; van der Put, C.E.; Stams, G.J.M.; Assink, M. Risk factors for child neglect: A meta-analytic review. Child Abus. Negl. 2018, 77, 198-210. [CrossRef] [PubMed]

17. Oskouie, F.; Zeighami, R.; Joolaee, S. Outcomes of parental mental illness on children: A qualitative study from Iran. J. Psychosoc. Nurs. Ment. Health Serv. 2011, 49, 32-40. [CrossRef] [PubMed]

18. Slominski, L. The Effects of Parental Mental Illness on Children: Pathways to Risk to Resilience from Infancy to Adulthood. Ph.D. Thesis, University of Michigan, Michigan, IL, USA, 2010. Available online: https:/ pdfs.semanticscholar.org/ef57/9a142fe7a2 4ff39936235f3536592e45660e.pdf?_ga=2.95786010.709128939.1589133602-1569656322.1589133602 (accessed on 27 June 2021).

19. Brennan, P.A.; Hammen, C.; Katz, A.R.; Le Brocque, R.M. Maternal depression, paternal psychopathology, and adolescent diagnostic outcomes. J. Consult. Clin. Psychol. 2002, 70, 1075-1085. [CrossRef]

20. Christiansen, H.; Anding, J.; Schrott, B.; Röhrle, B. Children of mentally ill parents-A pilot study of a group intervention program. Front. Psychol. 2015, 6, 1494. [CrossRef] [PubMed]

21. Leijdesdorff, S.; van Doesum, K.; Popma, A.; Klaassen, R.; van Amelsvoort, T. Prevalence of psychopathology in children of parents with mental illness and/or addiction. Curr. Opin. Psychiatry 2017, 30, 312-317. [CrossRef]

22. Aazh, H.; Landgrebe, M.; Danesh, A.A. Parental mental illness in childhood as a risk factor for suicidal and self-harm ideations in adults seeking help for tinnitus and/or hyperacusis. Am. J. Audiol. 2019, 28, 527-533. [CrossRef] [PubMed]

23. De Bellis, M.D.; Broussard, E.R.; Herring, D.J.; Wexler, S.; Moritz, G.; Benitez, J.G. Psychiatric co-morbidity in caregivers and children involved in maltreatment: A pilot research study with policy implications. Child Abus. Negl. 2001, 25, 923-944. [CrossRef]

24. Manning, C.; Gregoire, A. Effects of parental mental illness on children. Psychiatry 2008, 8, 7-9. [CrossRef]

25. Foster, K.; O'Brien, L.; McAllister, M. Addressing the needs of children of parents with a mental illness. Curr. Approaches. Contemp. Nurse 2005, 18, 67-80. [CrossRef]

26. Friedman, S.H.; McEwan, M.V. Treated mental illness and the risk of child abuse perpetration. Psychiatr. Serv. 2018, 69, 211-216. [CrossRef]

27. Lombardo, K.L.; Motta, R.W. Secondary trauma in children of parents with mental illness. Traumatology 2008, 14, 57-67. [CrossRef] 
28. Johnson, J.G.; Cohen, P.; Kasen, S.; Brook, J.S. Maternal psychiatric disorders, parenting, and maternal behavior in the home during the child rearing years. J. Child Fam. Stud. 2006, 15, 97-114. [CrossRef]

29. Sidebotham, P.; Golding, J.; The ALSPAC Study Team. Child maltreatment in the 'Children of the Nineties' A longitudinal study of parental risk factors. Child Abus. Negl. 2001, 25, 1177-1200. [CrossRef]

30. Dunn, B. Growing up with a psychotic mother: A retrospective study. Am. J. Orthopsychiatry 1993, 63, 177-189. [CrossRef]

31. Chowdry, H. Estimating the Prevalence of the "Toxic Trio": Evidence from the Adult Psychiatric Morbidity Survey; Children's Commissioner's Office: Children's Commissioner for England: London, UK, 2018. Available online: https://www.drugsandalcohol.ie/30 255/1/Vulnerability-Technical-Report-2-Estimating-the-prevalence-of-the-toxic-trio.pdf (accessed on 27 June 2021).

32. Adshead, G. Parenting and personality disorder: Clinical and child protection implications. BJPsych Adv. 2015, 21, 15-22. [CrossRef]

33. Dutton, D.G.; Denny-Keys, M.K.; Sells, J.R. Parental personality disorder and its effects on children: A review of current literature. J. Child Custody Res. 2011, 8, 268-283. [CrossRef]

34. Laulik, S.; Chou, S.; Browne, K.; Allam, J. The link between personality disorder and parenting behaviors: A systematic review. Aggress. Violent Behav. 2013, 18, 644-655. [CrossRef]

35. Steele, K.R.; Townsend, M.L.; Grenyer, B.F.S. Parenting and personality disorder: An overview and meta-synthesis of systematic reviews. PLoS ONE 2019, 14, e0223038. [CrossRef]

36. Stepp, S.D.; Whalen, D.J.; Pilkonis, P.A.; Hipwell, A.E.; Levine, M.D. Children of mothers with borderline personality disorder: Identifying parenting behaviors as potential targets for intervention. Personal. Disord. 2011, 3, 76-91. [CrossRef]

37. Wiehe, V.R. Empathy and narcissism in a sample of child abuse perpetrators and a comparison sample of foster parents. Child Abus. Negl. 2003, 27, 541-555. [CrossRef]

38. Seeman, M.V. Intervention to prevent child custody loss in mothers with schizophrenia. Schizophr. Res. Treat. 2012, $2012,796763$. [CrossRef]

39. Bussières, È.-L.; Godbout, E.; Lachance, V.; Drapeau, S. L'efficacité des interventions éducatives de groupe à l'intention des parents qui vivent une séparation conflictuelle: Une méta-analyse [The effectiveness of group educational interventions for parents who experience a conflicted separation: A meta-analysis]. Can. Psychol./Psychol. Can. 2020. [CrossRef]

40. Hanson, K.E.; Saul, D.H.; Duryea, E.R.; Painter, M.; Vanderploeg, J.J. Family-based recovery: An innovative collaboration between community mental health agencies and child protective services to treat families impacted by parental substance Use. Child Abus. Rev. 2019, 28, 69-81. [CrossRef]

41. Kuschel, A.; Granic, M.; Hahlweg, K.; Hartung, D. Children of mentally ill parents. Effects of a therapy-integrated family intervention. Verhaltenstherapie 2016, 26, 83-90. [CrossRef]

42. Thanhäuser, M.; Lemmer, G.; de Girolamo, G.; Christiansen, H. Do preventive interventions for children of mentally ill parents work? Results of a systematic review and meta-analysis. Curr. Opin. Psychiatry 2017, 30, 283-299. [CrossRef] [PubMed]

43. Greenberg, L.S. Emotion-Focused Therapy: Coaching Clients to Work through Their Feelings, 2nd ed.; American Psychological Association: Washington, DC, USA, 2015. [CrossRef]

44. Paivio, S.C.; Pascual-Leone, A. Emotion-Focused Therapy for Complex Trauma: An Integrative Approach; American Psychological Association: Washington, DC, USA, 2015. [CrossRef]

45. Goldman, R.N.; Greenberg, L.S.; Angus, L. The effects of adding emotion-focused interventions to the client-centered relationship conditions in the treatment of depression. Psychother. Res. 2006, 16, 537-549. [CrossRef]

46. Timulak, L.; McElvaney, J.; Keogh, D.; Martin, E.; Clare, P.; Chepukova, E.; Greenberg, L.S. Emotion-focused therapy for generalized anxiety disorder: An exploratory study. Psychotherapy 2017, 54, 361-366. [CrossRef] [PubMed]

47. Watson, J.C.; Saedi Chekan, S.; McMullen, E. Emotion-focused psychotherapy for GAD: Individual case comparison of a good and poor outcome case. Pers.-Cent. Exp. Psychother. 2017, 16, 118-139. [CrossRef]

48. Shahar, B.; Bar-Kalifa, E.; Alon, E. Emotion-focused therapy for social anxiety disorder: Results from a multiple-baseline study. J. Consult. Clin. Psychol. 2017, 85, 238-249. [CrossRef] [PubMed]

49. Lafrance Robinson, A.; Dolhanty, J.; Stillar, A.; Henderson, K.; Mayman, S. Emotion-focused family therapy for eating disorders across the lifespan: A pilot study of a 2-Day transdiagnostic intervention for parents. Clin. Psychol. Psychother. 2016, 23, 14-23. [CrossRef]

50. Greenberg, L.S. Emotion-Focused Therapy; American Psychological Association: Washington, DC, USA, 2011.

51. Greenberg, L.S. The therapeutic relationship in emotion-focused therapy. Psychotherapy 2014, 51, 350-357. [CrossRef] [PubMed]

52. Elliott, R.; Watson, J.C.; Goldman, R.N.; Greenberg, L.S. Learning Emotion-Focused Therapy: The Process-Experiential Approach to Change; American Psychological Association: Washington, DC, USA, 2004.

53. Goldman, R.N.; Greenberg, L.S. Case Formulation in Emotion-Focused Therapy: Co-Creating Clinical Maps for Change; American Psychological Association: Washington, DC, USA, 2015.

54. Pos, A.E.; Paolone, D.A. Emotion-focused therapy for personality disorders. In Clinical Handbook of Emotion-Focused Therapy Greenberg, L.S., Goldman, R.N., Eds.; American Psychological Association: Washington, DC, USA, 2019; pp. 381-402. [CrossRef]

55. Pascual-Leone, A.; Bierman, R.; Arnold, R.; Stasiak, E. Emotion-focused therapy for incarcerated offenders of intimate partner violence: A 3-year outcome using a new whole-sample matching method. Psychother. Res. 2011, 21, 331-347. [CrossRef] [PubMed]

56. Pascual-Leone, A.; Gilles, P.; Singh, T.; Andreescu, C.A. Problem anger in psychotherapy: An emotion-focused perspective on hate, rage, and rejecting anger. J. Contemp. Psychother. 2013, 43, 83-92. [CrossRef] 
57. Leal, J.; Cunha, C.; Santos, A.; Salgado, J. Helping clients victimized by intimate partners through stages of change: An emotion-focused approach. J. Contemp. Psychother. 2021, 51, 41-48. [CrossRef]

58. Kolko, D.J.; Iselin, A.M.R.; Gully, K.J. Evaluation of the sustainability and clinical outcome of Alternatives for Families: A Cognitive-behavioral therapy (AF-CBT) in a child protection center. Child Abuse Neglect 2011, 35, 105-116. [CrossRef]

59. Kumpfer, K.L.; Magalhães, C. Strengthening Families program: An evidence-based family intervention for parents of high-risk children and adolescents. J. Child Adolesc. Subst. Abus. 2018, 27, 174-179. [CrossRef] 